\title{
ANÁLISIS MORFOTECTÓNICO EN EL PIEDEMONTE SUROCCIDENTAL DEL ANTEPAIS ANDINO, SIERRAS PAMPEANAS OCCIDENTALES, SAN JUAN, ARGENTINA
}

\author{
MORPHOTECTONIC ANALYSIS IN THE SOUTHWEST PIEDMONT OF THE ANDEAN \\ FORELAND, SIERRAS PAMPEANAS OCCIDENTALES, SAN JUAN, ARGENTINA
}

\section{Luis Martin ROTHIS ${ }^{1,2}$; Laura Patricia PERUCCA ${ }^{1,2}$, Paula SANTI MALNIS ${ }^{1,2,3}$; Ana PANTANO ZUÑIGA ${ }^{1,2}$; Juan Manuel ALCACER ${ }^{3,4}$; Federico Miguel HARO ${ }^{1}$; Nicolas VARGAS ${ }^{2}$}

${ }^{1}$ CIGEOBIO - Consejo Nacional de Investigaciones Científicas y Tecnológicas (CONICET). Gabinete de Neotectónica y Geomorfología. INGEO. Facultad de Ciencias Exactas, Físicas y Naturales. UNSJ, Av. Ignacio de La Roza y Meglioli s/n (5400), San Juan, Argentina; e-mail: mrothis@unsj-cuim.edu.ar

${ }^{2}$ Departamento Geología, Facultad de Ciencias Exactas, Físicas y Naturales, UNSJ

${ }^{3}$ Instituto y Museo de Ciencias Naturales, Facultad de Ciencias Exactas, Físicas y Naturales, UNSJ

${ }^{4}$ Departamento de Geofísica y Astronomía, Facultad de Ciencias Exactas, Físicas y Naturales, UNSJ

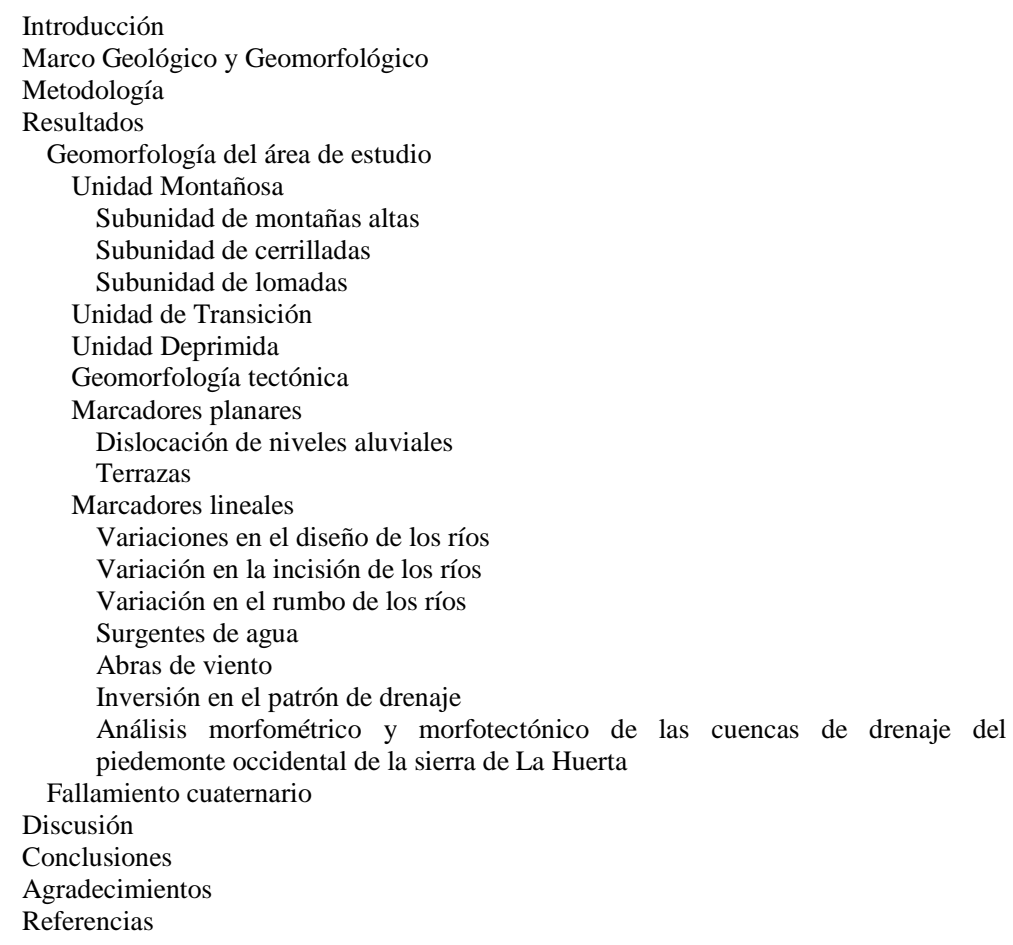

RESUMO - El retroarco andino, entre los $27^{\circ} \mathrm{S}$ y $33^{\circ} \mathrm{S}$, se caracteriza por ser una de las regiones con mayor sismicidad cortical en el mundo, siendo epicentro de importantes terremotos en el territorio argentino. Esta sismicidad produce una intensa deformación, provocando cambios en la morfología del terreno. En el sector occidental de Sierras Pampeanas Occidentales, en la sierra de la Huerta, se utilizó un SIG para diferenciar unidades geomorfológicas y determinar parámetros cualitativos y cuantitativos que permitieran caracterizar las geoformas identificadas y su relación con la actividad tectónica. La tectónica andina, que afecta la región desde los últimos 5 millones de años, es el principal factor que controla el paisaje de la región. Se diferenciaron tres unidades morfoestucturales y fallamiento con actividad tectónica cuaternaria, presentando abundantes indicadores morfotectónicos, como niveles aluviales dislocados, variación en el diseño y desvío de los ríos, aumento en su grado de incisión, surgentes de agua, abras de viento e inversión del patrón de drenaje, entre otros. El análisis de los indicadores morfotectónicos permitió identificar cómo la deformación disminuye hacia el sur y aumenta de este a oeste. Finalmente, es posible determinar que la deformación continúa activa, modificando el paisaje actual del piedemonte occidental de la sierra de la Huerta.

Palavras-chave: Sierras Pampeanas Occidentales; sierra de la Huerta; indicadores morfotectónicos; unidades morfoestructurales.

ABSTRACT - Between $27^{\circ} \mathrm{S}$ and $33^{\circ} \mathrm{S}$ the Andean backarc is one of the most seismically active region in the world, being epicenter of the most important crustal earthquakes that affected Argentina. Associated with the seismicity an intense deformation occurs, causing changes on the land surface morphology. In the western sector of the Sierras Pampeanas Occidentales, in the Sierra de la Huerta, a GIS analysis was applied to define geomorphological units and obtain qualitative and quantitative parameters that allowed characterizing the identified geoforms and their relation with tectonic activity. Andean tectonics affect this region for the last 5 millions of years, controlling it landscape evolution. Three morphostructural units and quaternary active faulting were identify, presenting abundant morphotectonic markers, such as dislocated alluvial levels, changes in river pattern, diversion of river courses, increasing degree of incision, water springs, wind gap and inversion of the pattern drainage, among others. The quantitative and qualitative analysis of the morphotectonic parameters shows that deformation decrease from North to South and increase from East to West. Concluding, according to morphotectonics parameters deformation is still active, modifying the present-day landscape in the Western piedmont of La Huerta range.

Keywords: Sierras Pampeanas Occidentales; sierra de la Huerta; morphotectonic markers; morphostructurals units. 


\section{INTRODUCCIÓN}

El levantamiento de la Cordillera de los Andes es atribuido a la subducción de la placa de Nazca por debajo del continente Sudamericano (Baranzangi \& Isacks, 1976, Isacks, 1988). En la región del retroarco Andino, entre los $27^{\circ} \mathrm{S}$ y $33^{\circ} \mathrm{S}$, se produce la mayor deformación tectónica cuaternaria (Costa et al., 2006); asociada con el segmento de subducción subhorizontal Pampeano (Baranzangi \& Isacks, 1976, Anderson et al.,
2007) (Figura 1a, b).

La subducción subhorizontal, en la región de antepaís, ha producido el levantamiento de bloques de basamento a través de anisotropías corticales, a los que se le asocia un elevado registro sísmico cortical (Ramos et al., 2002, Siame et al., 2005). Estos bloques de basamento conforman una serie de serranías denominadas Sierras Pampeanas Occidentales.

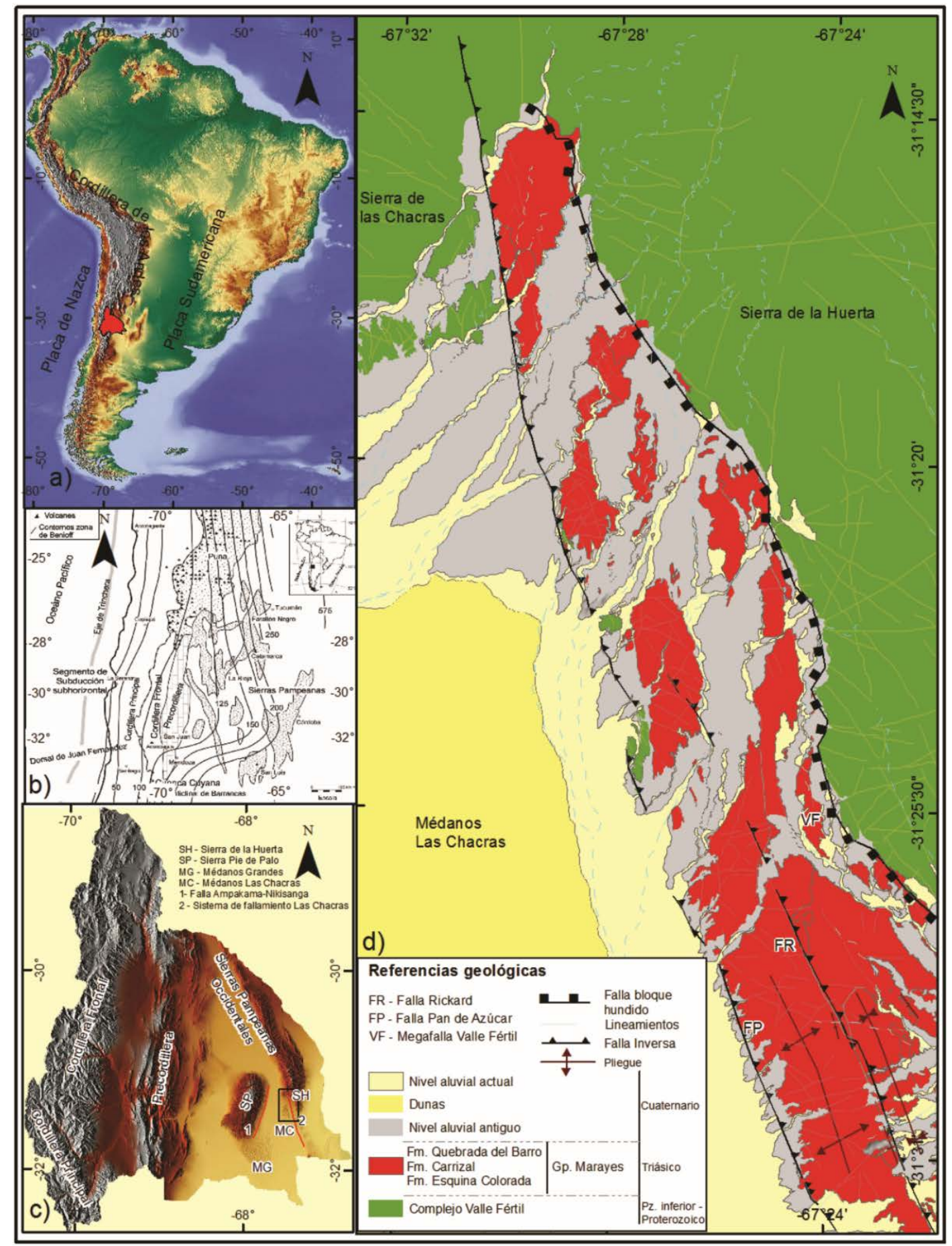

Figura 1 - a) Ubicación de la zona de estudio en el contexto de América del sur. b) Ubicación del segmento de subducción subhorizontal Pampeano (Mod. de Ramos et al., 2002). c) Ubicación del área de estudio dentro de la provincia de San Juan. d) Mapa geológico de la zona de estudio. 
El sector occidental de las Sierras Pampeanas Occidentales, en la provincia de San Juan, está integrado por serranías de orientación submeridional y separados por amplios valles. Estas serranías son elevadas principalmente por estructuras de fallamiento inverso con moderada a elevada inclinación hacia el este, a las cuales se les asocia sismicidad superficial, con profundidades menores de $70 \mathrm{~km}$ (Langer \& Bollinger, 1988). En la bajada pedemontana occidental de la sierra de la Huerta se ha reconocido el Sistema de fallamiento Las Chacras (Bastías et al., 1990), el que formaría parte de la megafalla Valle Fértil, considerada como una antigua estructura que ha sufrido reactivaciones a lo largo del tiempo geológico (Vujovich et al., 2007).

El Sistema de fallamiento Las Chacras presenta evidencia de actividad tectónica cuaternaria y ha sido estudiado por varios autores desde el punto de vista regional (Treo et al., 1997, Bastías et al., 1990, Pérez et al., 1997, Rothis et al., 2012). Sin embargo, en el presente estudio se efectuaron análisis geomorfológicos y morfotectónicos, utilizando diferentes indicadores morfotectónicos que permitieron identificar sectores con diferentes rangos de deformación. Además, entre los $27^{\circ} \mathrm{S}$ y $52^{\circ} \mathrm{S}$ se desarrolla en el borde oriental de los Andes una angosta franja de máxima aridez, denominada Diagonal Árida
(Bruniard, 1982); estas condiciones climáticas juegan un rol importante en la excelente preservación de evidencias geomorfológicas de la actividad tectónica cuaternaria. Como se intenta demostrar aquí mediante criterios geomorfológicos y geológicos, en la región de Sierras Pampeanas Occidentales, la actividad tectónica continua todavía activa.

Por lo tanto, el objetivo de este trabajo es poder identificar y cuantificar la deformación presente en el piedemonte occidental de la sierra de la Huerta, mediante un estudio detallado de los cambios en el patrón de drenaje, en la sinuosidad de ríos, en su grado de incisión, las morfologías de las cuencas de drenaje y la deformación de los niveles aluviales, entre otros.

Como resultado de estos estudios, se pretende explicar la relación entre las diferentes unidades geomorfológicas y la tectónica cuaternaria que afecta la región de antepaís andino; y la utilización de los diferentes indicadores morfotectónicos en el reconocimiento de áreas con evidencias directas o indirectas de tectónica activa. Además, los resultados obtenidos permitirán un mejor conocimiento de la evolución de la actividad neotectónica de las Sierras Pampeanas Occidentales, una parte clave del antepaís andino fracturado, con una elevada sismicidad cortical y epicentro de grandes terremotos históricos destructivos.

\section{MARCO GEOLÓGICO Y GEOMORFOLÓGICO}

La interacción entre las placas litosféricas de Sudamérica y de Nazca, donde esta última subducta la primera, es la responsable de que la deformación cuaternaria esté concentrada a lo largo de más de 8000 km dentro de la Cordillera Andina (Costa et al., 2006) (Figura 1a).

El segmento que abarca la Cordillera de San Juan y Mendoza se caracteriza porque la placa de Nazca tiene un estilo de subducción subhorizontal (flat slab), (Ramos et al., 2002) (Figura 1b). Esta geometría de subducción genera por un lado una fuerte correlación entre la distribución y las características de la deformación cuaternaria hacia el retroarco andino, y por otro, la concentración de más del $90 \%$ de la deformación cuaternaria documentada en Argentina, particularmente, entre los $30^{\circ} \mathrm{S}$ y $33^{\circ} \mathrm{S}$ (Ramos, 1999; Costa et al., 2000).

Asociada a esta subducción plana en la región de antepaís se produce una fragmentación del territorio, constituyendo lo que se conoce como Sierras Pampeanas. Las Sierras Pampeanas se definen como una serie serranías conformadas por bloques basculados de basamento que se encuentran limitados en su borde occidental por antiguas fallas buzantes al este que se horizontalizan en profundidad, al encontrar el limite frágil-dúctil dentro de la corteza (Ramos, 1999). Costa (1999), mencionó la presencia de deformaciones andinas en la zona de intraplaca distantes a más de $700 \mathrm{~km}$ de donde se ubica la fosa oceánica, con una expresión superficial aislada y de escasa extensión areal.

Comúnmente se había considerado que estas típicas fallas de intraplaca tenían largos periodos de recurrencia, sin embargo estudios posteriores han sugerido que las mismas han tenido tiempos de retorno en tiempos pre 
históricos (Costa et al., 2001, Villalba \& Sagripanti, 2014). Por otro lado, dentro de los escasos registros de ruptura superficial en el ámbito de Sierras Pampeanas, se puede mencionar el caso de la falla AmpacamaNiquizanga (Figura 1c) ubicada en el extremo sureste de la sierra de Pie de Palo (provincia de San Juan).

Esta deformación está asociada con el epicentro del terremoto de 1977 que afectó a la localidad de Caucete y la ciudad de San Juan (Bastías et al., 1990; Siame et al., 2005; Vergés et al., 2007). La mencionada falla pertenece al sistema de fallamiento Pie de Palo, definido por Bastías et al. (1990), el cual incluye evidencias neotectónicas ubicadas al este y norte de la sierra Pie de Palo. Inmediatamente al este de este sistema de fallamiento $y$ vinculado estructuralmente se definió el sistema de fallamiento Las Chacras (Bastías et al., 1990), asociado al frente de fracturación de la sierra de Valle Fértil (Figura 1c).

Desde el punto de vista de la sismicidad, este sector se caracteriza por tener una elevada cantidad de registros sísmicos; Regnier et al. (1992) determinaron que los eventos registrados entre 20-25 km bajo la sierra de Pie de Palo podrían representar un décollement que conecta en profundidad Precordillera Oriental con Sierras Pampeanas. Por otro lado, varios autores (Smalley et al., 1993, Alvarado \& Beck, 2006; Siame et al., 2015) mencionan que la mayoría de los eventos registrados en este sector de Sierras Pampeanas, fueron determinados como eventos corticales con profundidades que varían entre los 10 y los $35 \mathrm{~km}$.
Al este de la sierra de Pie de Palo se encuentra la sierra de la Huerta (Figura 1c). Esta última está caracterizada por rocas del basamento cristalino, metamorfitas de alto grado, que alcanzan facies de anfibolitas y granulitas y una extensa zona de metabasitas acrecionadas a la sierra de la Huerta durante el Proterozoico Superior y Paleozoico Inferior (Vujovich et al., 2007) (Figura 1d). Hacia el suroeste de la sierra de la Huerta se reconoce la presencia de depósitos correspondientes al Grupo Marayes, sedimentitas continentales de edad triásica, que yacen discordantemente por encima del basamento cristalino. Además, se identificaron depósitos cuaternarios de fanglomerados y conglomerados correspondientes a niveles aluviales con edades que van desde el Pleistoceno hasta la actualidad.

Regionalmente, el ambiente geomorfológico se manifiesta en bloques de basamento, en un área de antepaís fracturado por la orogenia Andina. Los bloques ascendidos constituyen las sierras, mientras que las depresiones originadas entre los bloques conforman las cuencas sedimentarias, donde se desarrollan los ambientes de acumulación como abanicos y conos aluviales, bajadas, playas limosas, dunas y playas salinas en el sector distal (Vujovich et al., 2007).

En la región oriental, se desarrollan los grandes campos de dunas denominados Médanos Grandes y Médanos de las Chacras, asignados al Pleistoceno tardío-Holoceno (Tripaldi \& Forman, 2007). Estos campos de dunas resultan ser remanentes de una superficie eólica mucho más extensa en el pasado y que actualmente están sujetos a erosión (Tripaldi, 2002).

\section{METODOLOGÍA}

Para el análisis del área de estudio, se realizaron tareas de gabinete y de campo. Las tareas de gabinete incluyeron la confección de un mapa geomorfológico y morfotectónico de detalle del piedemonte occidental de la sierra de La Huerta, a partir de imágenes satelitales Landsat Thematic Mapper (http://glcf.umd.edu/ data/) y fotografías aéreas.

En el mapa se realizó la discriminación de diferentes unidades morfoestructurales, el análisis del diseño de la red de drenaje y el relevamiento de las principales estructuras geológicas. El tratamiento de bandas permitió resaltar diferentes aspectos del relieve, como estructuras sedimentarias, tectónicas, litologías, áreas con mayor y menor cubierta vegetal y zonas con diferente contenido de humedad.

Los datos relevados en el mapa se complementaron con controles de campo para su corroboración y caracterización. En las labores de campo se describieron además las rocas que formaban cada unidad geomorfológica, su orientación espacial, sus alturas relativas, la presencia o ausencia de barniz del desierto y la relación espacial de las unidades geomorfológicas.

Para la diferenciación de las distintas unidades eólicas del Médano Las Chacras se tuvo en cuenta las dimensiones de las distintas formas de acumulación, su geometría, orientación espacial y distribución en el espacio. 
En forma simultánea se realizó una evaluación de indicadores morfotectónicos planares y lineales (Burbank \& Anderson, 2001) identificados en el área de estudio. Para que un rasgo geomorfológico sea considerado planar, tiene que tener una extensión areal considerable, en tanto que marcadores lineales son aquellos rasgos con geometría estrecha en relación a su longitud (Burbank \& Anderson, 2001).

Se identificaron marcadores planares como terrazas, superficies de erosión o glacís; y marcadores lineales tales como escarpas de falla, cauces de ríos, crestas de cerrilladas o sierras, alineación de vegetación y de vertientes (Audemard, 1999, Perucca et al., 2015).

Por otro lado, se analizaron parámetros morfométricos asociados a la red de drenaje, para determinar la respuesta de esta a la deformación tectónica (Keller \& Pinter, 1996). Los parámetros morfométricos fueron calculados mediante la utilización de un SIG (Sistema de Información Geográfica).

En una zona con tectónica activa, movimientos verticales del terreno, influencian la morfología de los ríos, provocando variaciones en la sinuosidad de los mismos (Ouchi, 1985, Keller \& Pinter, 1996, Perucca et al., 2014). Estas variaciones pueden ser cuantificadas mediante el índice de sinuosidad (S), que es la relación entre la longitud del cauce (C) y la longitud del valle (V) (Keller \& Pinter, 1996). Los valores de C y V se obtuvieron a partir del uso de un SIG (Sistema de Información Geográfica) con la relación:

$$
S=C / V
$$

Otro aspecto que se analizó es la morfología de cuencas hidrográficas ya que su estudio permite identificar zonas con tectónica activa (Bull, 2009). Para esto se analizó la morfología de cuencas presentes en el piedemonte occidental de la sierra de la Huerta, caracterizándolas a partir de parámetros morfométricos como Índice de compacidad $(\mathrm{Kc})$, Índice de circularidad (Rc), Radio de Elongación (Re) y Factor de Forma (Ff) (Tabla 1).

Asimismo, se cuantificó la asimetría de las diferentes cuencas hidrográficas, la cual permite determinar el basculamiento del terreno; para esto se utilizó el índice de Factor de Asimetría AF (Hare \& Gardner, 1985).

$$
A F=100 *(A d / A t)
$$

Siendo Ad el área de la cuenca ubicada en la margen derecha del colector principal y At es el área total de la cuenca. Un valor de 50 sugiere que la cuenca no está afectada por basculamiento; en tanto que un valor de AF mayor o menor de 50 indica un basculamiento del terreno desde la derecha o desde la izquierda respectivamente (Hare \& Gardner, 1985).

También se tomaron muestras de sedimentos en cuñas coluviales, las cuales fueron datadas por Luminiscencia Ópticamente Estimulada (LOE) a través del método SAR, en los laboratorios Datação, Comércio y Prestação de Serviços Limitada, São Pablo, Brasil. Estas dataciones permitieron acotar temporalmente el nivel aluvial más antiguo.

\begin{tabular}{|c|c|c|}
\hline Índice de compacidad & $K c=0,28(P / \sqrt{ } A)$ & Gravelius, 1914 \\
\hline Índice de circularidad & $\mathrm{Rc}=4 \pi \mathrm{A} / \mathrm{P}^{2}$ & Miller, 1953 \\
\hline Radio de Elongación & $\operatorname{Re}=(\sqrt{ } 4 \mathrm{~A} / \pi) / \mathrm{L}$ & Schumm,1956 \\
\hline Factor forma & $\mathrm{Ff}=\mathrm{A} / \mathrm{L}^{2}$ & Horton, 1932 \\
\hline
\end{tabular}

Tabla 1 - Parámetros morfométricos relacionados a la forma que presenta una cuenca de drenaje.

A=área; $\mathrm{P}=$ perímetro, $\mathrm{L}=$ longitud de la cuenca

\section{RESULTADOS}

\section{Geomorfología del área de estudio}

Las unidades morfoestructurales son definidas como aquellas formas que adopta el relieve como resultado de levantamientos, hundimientos y desplazamientos de la corteza terrestre a causa de la tectónica, con la posterior acción de la erosión y sedimentación (Gutiérrez Elorza, 2008). Además, ambos procesos están condicionados por la naturaleza de las rocas.
Es decir que la tectónica y litología constituyen los dos elementos principales que condicionan el desarrollo y evolución temporal del relieve de la región.

Las unidades morfoestructurales reconocidas en el faldeo occidental de la sierra de La Huerta se han agrupado en tres categorías principales que son (Figura 2a y b): Unidad Montañosa; Unidad de Transición; Unidad Deprimida. 


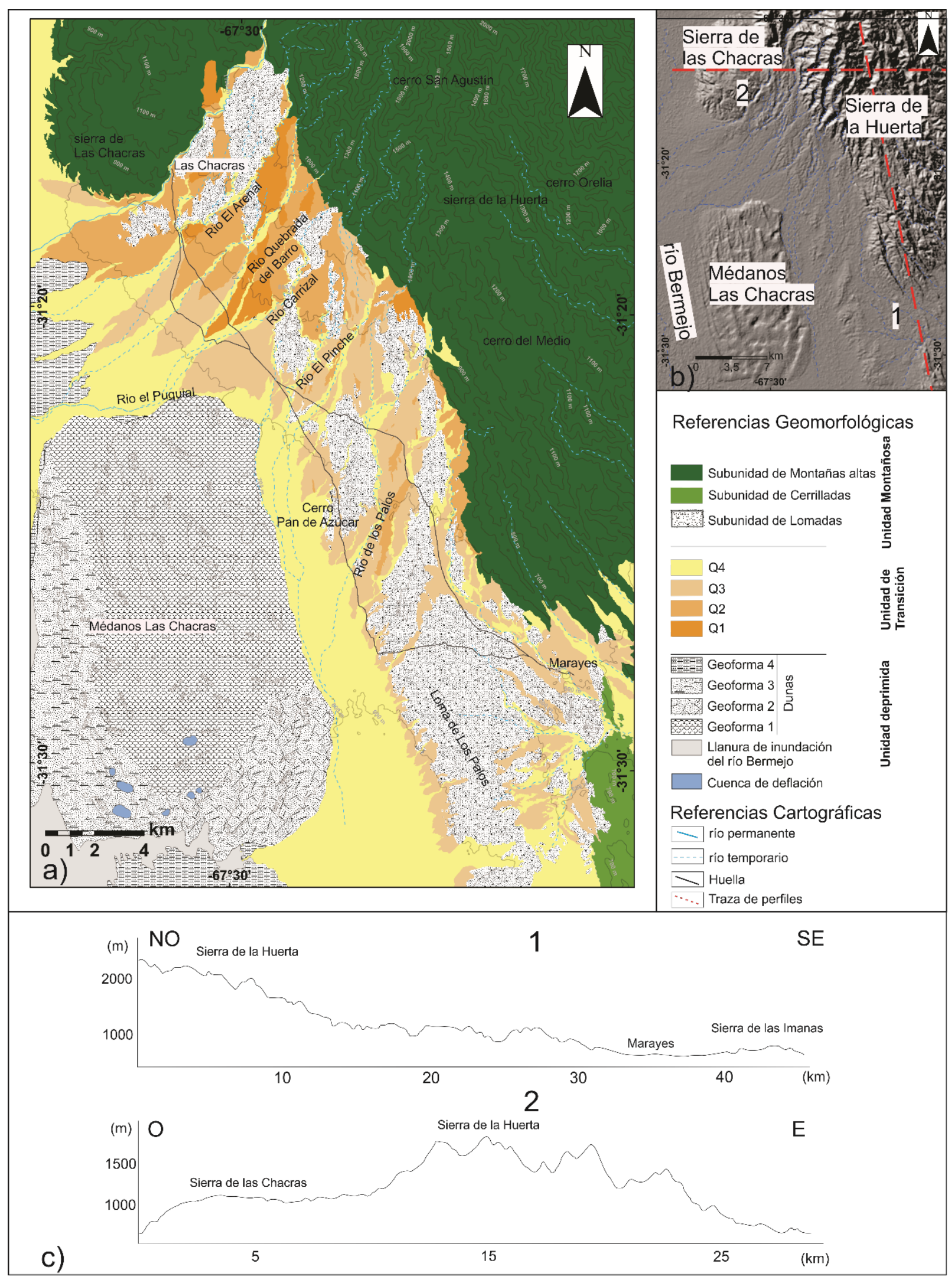

Figura 2 - a) Mapa geomorfológico de la zona de estudio. b) Imagen de sombras de la zona de estudio, con líneas rojas se indica la traza de perfiles topográficos. c) Perfiles topográficos, mostrando variaciones de la morfología del terreno.

\section{Unidad Montañosa}

Esta unidad se corresponde con aquellos relieves más prominentes que se destacan en la zona de estudio. Dentro de esta unidad se identificaron tres subunidades: montañas altas, de cerrilladas y de lomadas. Subunidad de montañas altas

La subunidad de montañas altas corresponde a aquellos afloramientos de mayor altura y con rumbo NO que resaltan en el paisaje, ubicados 
al este de la zona de estudio.

Las mayores elevaciones pertenecen a la sierra de La Huerta, cuya altura máxima es de $2060 \mathrm{~m}$ snm (metros sobre el nivel del mar). Las alturas de los cordones montañosos del área disminuyen de norte a sur, siendo éste un rasgo muy notorio en el relieve del área.

Por ejemplo, el perfil longitudinal de la sierra de La Huerta, muestra como ésta disminuye su altura hacia el sur, con una geometría escalonada, hasta la localidad de Marayes, donde pierde expresión morfológica (Figura 2c).

Los perfiles transversales de los cordones montañosos son asimétricos, siendo el faldeo occidental aquel que presenta mayor inclinación, y su flanco oriental el de menor pendiente (Figura 2c).

Los perfiles topográficos transversales a la sierra de La Huerta, muestran además la fuerte incisión de los ríos que la atraviesan y lo escarpado de sus interfluvios.

Dentro de la unidad montañosa alta se destacan, de norte a sur, el cerro San Agustín, cerro Orelia y el cerro del Medio (Figura 2a). Hacia el norte se ubica la sierra de las Chacras, la cual presenta una altura máxima de $1154 \mathrm{~m}$ snm.

Estos cordones montañosos están constituidos por rocas metamórficas de edad proterozoica y paleozoica inferior, correspondientes al Complejo Valle Fértil (Figura 1d).

\section{Subunidad de cerrilladas}

Hacia el sur de la localidad de Marayes emergen una serie de pequeñas cerrilladas pertenecientes a la sierra de las Imanas. Esta sierra presenta una altura máxima de $750 \mathrm{~m}$ snm, con una orientación NO y que muestra también un perfil asimétrico, con su faldeo occidental más abrupto en relación al flanco oriental.

Esta subunidad está compuesta también por rocas del Complejo Valle Fértil (Figuras 1d y 2a).

\section{Subunidad de lomadas}

Esta subunidad se desarrolla en la parte central de la zona de estudio, hacia el oeste de la sierra de La Huerta, y al este de los Médanos de Las Chacras (Figura 2a).

Está caracterizada por un relieve positivo, pero que contrasta con respecto a la unidad montañosa por tener una litología diferente y presentar alturas menores. Las mayores elevaciones topográficas son aquellas localizadas en el sector norte del área de estudio, en las cercanías al caserío de Las Chacras, donde alcanzan los $945 \mathrm{~m} \mathrm{snm}$, disminuyendo hacia el sur hasta los $685 \mathrm{~m} \mathrm{snm}$ (Figura 2a y b).

Este relieve intermedio presenta una geometría particular como una franja de ancho constante con dirección elongada en sentido NO. Además, posee una morfología suavizada y ondulada (Figura 3a, b, c y d) con el desarrollo de quebradas no muy profundas, con desniveles entre la base y la cima de los cerros de entre 40 y $50 \mathrm{~m}$.

Hacia el sector oriental se observa el desarrollo de un paisaje típico de tierras malas (badlands) (Figura 3d).

La subunidad de lomadas está disectada por lineamientos NNE, que generaron el desarrollo de lomadas saltuarias, orientadas en dirección NO y compuestas principalmente por rocas triásicas del Grupo Marayes, asignadas a la Formación Quebrada del Barro, Formación El Carrizal y Formación Esquina Colorada; de ellas la de mayor distribución areal es la Formación Quebrada del Barro. En forma minoritaria se observaron rocas metamórficas, correspondientes al basamento cristalino del Complejo Valle Fértil.

Estas últimas son comunes en el sector norte de la zona de estudio en las cercanías a la sierra de Las Chacras y en el cerro Pan de Azúcar (Figura 1c).

Esta subunidad posee además una fina cubierta de guijarros, provenientes del retrabajamiento de rocas triásicas y del basamento, que en algunos sectores enmascaran la estratificación y foliación de las rocas aflorantes.

\section{Unidad de Transición}

La unidad geomorfológica correspondiente a la unidad de transición o piedemonte se extiende desde el frente montañoso hasta el nivel de base de erosión local, en este caso el río Bermejo (Figura 2b).

Esta unidad está integrada principalmente por glacis cubiertos (Gutiérrez Elorza, 2008), ya que las distintas unidades de edad triásica se encuentran biseladas por una superficie plana de suave pendiente sobre la que se apoya una fina cubierta de depósitos aluviales cuaternarios. 

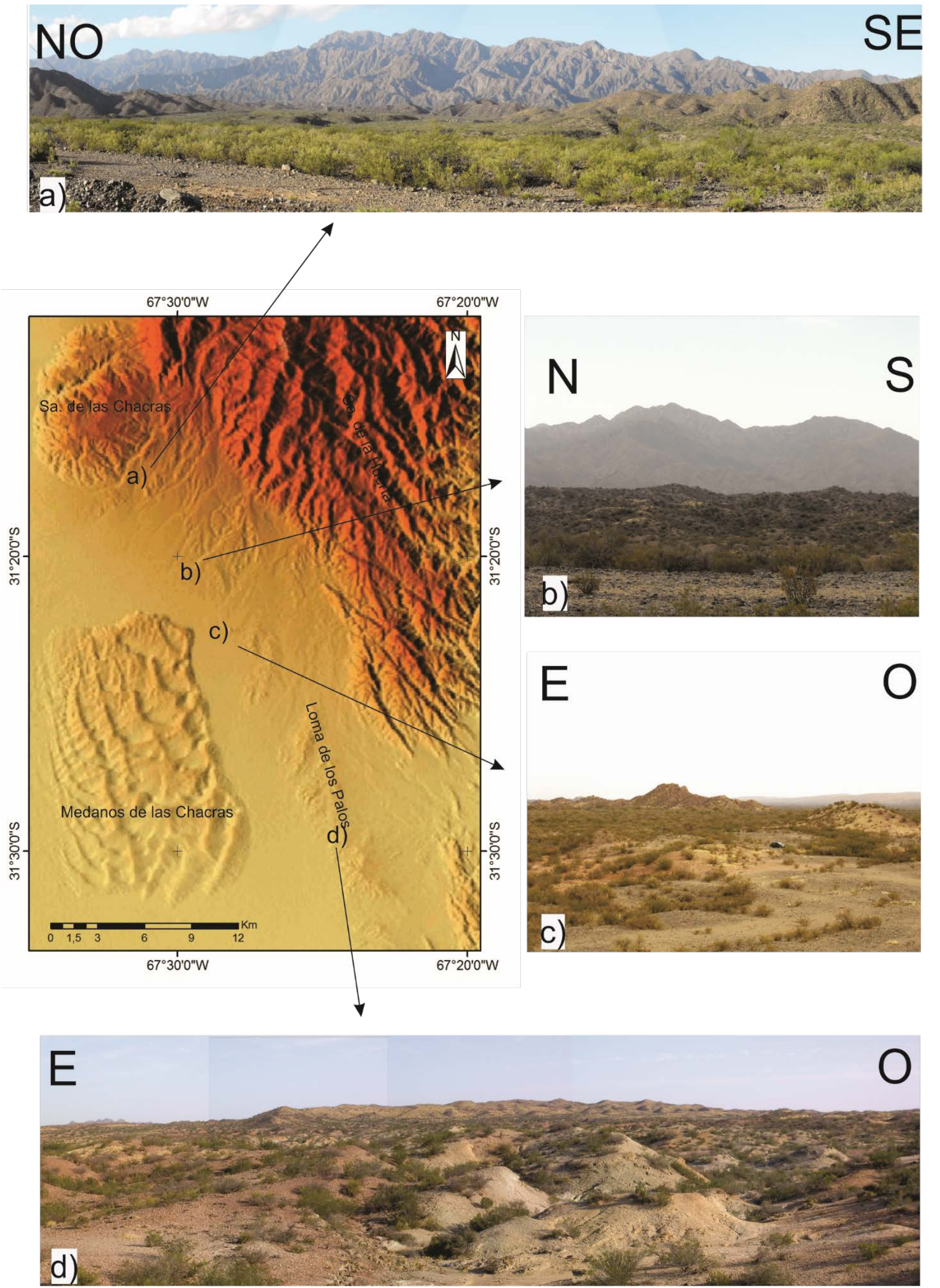

Figura 3 - En las fotografias a) y b) se puede apreciar las subunidad de montañas altas (hacia el fondo de la imagen) y la subunidad de lomadas. En c) y d) se observa la morfología ondulada y suavizada de la subunidad de lomadas.

Dentro de esta unidad, se identificaron la disposición topográfica, el grado de incisión cuatro niveles aluviales que, teniendo en cuenta de la red de drenaje que los afecta y las 
diferencias en las tonalidades de las superficies, con la presencia o no de barniz del desierto, se clasificaron como Q1, Q2, Q3 y Q4.

Esta nomenclatura se ha usado para asignarle a estos depósitos edades relativas, siendo el más antiguo el nivel Q1 (el de posición topográfica más elevada e incisión de los ríos) y el nivel Q4 el más reciente.

Además, las dataciones de LOE (Luminiscencia Ópticamente Estimulada) efectuadas en algunos de estos niveles han permitido acotar temporalmente la edad de los mismos.

El nivel más antiguo reconocido en la zona de estudio es Q1con edades mayores a $47.830 \pm$ 8.340 años, que es la edad obtenida por el método de LOE en una cuña coluvial, generada a partir del colapso de material (Q1) proveniente del bloque colgante, como consecuencia del movimiento de la falla Pan de Azúcar.

Este nivel aluvial (Q1) forma relictos dispersos, ubicados principalmente en la zona norte y en las cercanías de la sierra de La Huerta (Figura 2a).

Presenta formas elongadas en sentido NE, de color gris oscuro, su superficie es plana y tiene aspecto redondeado en sus bordes, se encuentra topográficamente a mayor altura con respecto al resto de los niveles aluviales reconocidos.

En este nivel se observa que la red de drenaje no es muy densa, pero está fuertemente incidida.

En su superficie se identificaron aglomerados masivos, con bloques de hasta 80 cm (diámetro mayor) de tonalitas, anfibolitas y guijarros de 20 a $15 \mathrm{~cm}$ de tonalitas, anfibolitas, cuarzo.

La matriz del depósito está compuesta por arenas y gravas finas y se destaca la presencia de barniz del desierto recubriendo los clastos ubicados en la superficie del nivel aluvial (Figura 4a).

El nivel Q2 se reconoce en afloramientos dispersos en el sector norte y en las cercanías de la sierra de La Huerta y de Las Chacras (Figura 2a). Al igual que el nivel anterior presenta formas elongadas en sentido NE de color gris claro a oscuro y posee alturas intermedias entre el nivel Q1 y Q3.

Presenta una red de drenaje densa, con cauces que drenan con direcciones de escurrimiento principalmente de NE a SO.

Está compuesto por aglomerados masivos, con bloques de hasta $60 \mathrm{~cm}$ (predominan entre 40 y 60) de tonalitas granudas máficas y gneises; guijarros de 20 a $15 \mathrm{~cm}$ de la misma composición y también se han observado clastos de calizas, gneises bandeados, metamorfitas con abundante feldespato potásico y cuarzo; guijas de 2 a $5 \mathrm{~cm}$ de granudas máficas, esquistos micáceos y cuarzo.

Los bloques y guijarros son subredondeados a subangulosos y la matriz está compuesta por arenas y gravas finas.

También se observa la presencia de barniz del desierto (Figura 4b y c).

El nivel Q3 se encuentra de manera dispersa aunque tiene mayor extensión areal que los niveles más antiguos reconocidos. Se ubica en el sector noroeste y sureste de la zona de estudio $\mathrm{y}$ presenta formas elongadas con direcciones NE y N-S (Figura 2a). Se caracteriza por presentar un color gris claro, con desarrollo de una red drenaje densa pero de grado intermedio de incisión en relación con los niveles descriptos precedentemente.

Debido a su gran extensión, su composición varía localmente, pero en general se describe como un aglomerado masivo, en el que se reconocen tres modas, determinadas en función del tamaño de sus clastos: bloques de 30 a 40 $\mathrm{cm}$ de rocas granudas máficas, metamorfitas granudas con alta proporción de feldespato potásico, gneises, tonalitas, esquistos micáceos; guijones de 20 a $10 \mathrm{~cm}$ de tonalitas, gneises, granudos con feldespato potásico, cuarzo, esquistos micáceos; y guijas de $3 \mathrm{~cm}$ de tonalita, esquistos granatíferos, cuarzo lechoso, mármoles y gneises -diorita (Figura 4d y e).

La matriz está compuesta por fragmentos que varían en tamaño entre arenas y gravas finas.

El nivel Q4 está integrado por los depósitos aluviales de los ríos intermitentes actuales con sus respectivas planicies de inundación (Figuras 2a y 4f y g).

Está distribuido en las zonas topográficas más bajas, hacia el sur y suroeste de la zona de estudio principalmente.

En la zona central están circunscriptos a los ríos más importantes. Tiene color gris muy claro, una densa red drenaje en la cual se pueden distinguir ríos con mayor grado de 
incisión, que son aquellos cauces más activos mientras que los que tienen menor grado de incisión son los que tienen menor poder de arrastre.
Las direcciones de escurrimiento de los ríos en el sector NO del área de estudio son de NE a $\mathrm{SO}$, en tanto que hacia el sur los ríos drenan de norte a sur (Figura 2 a).

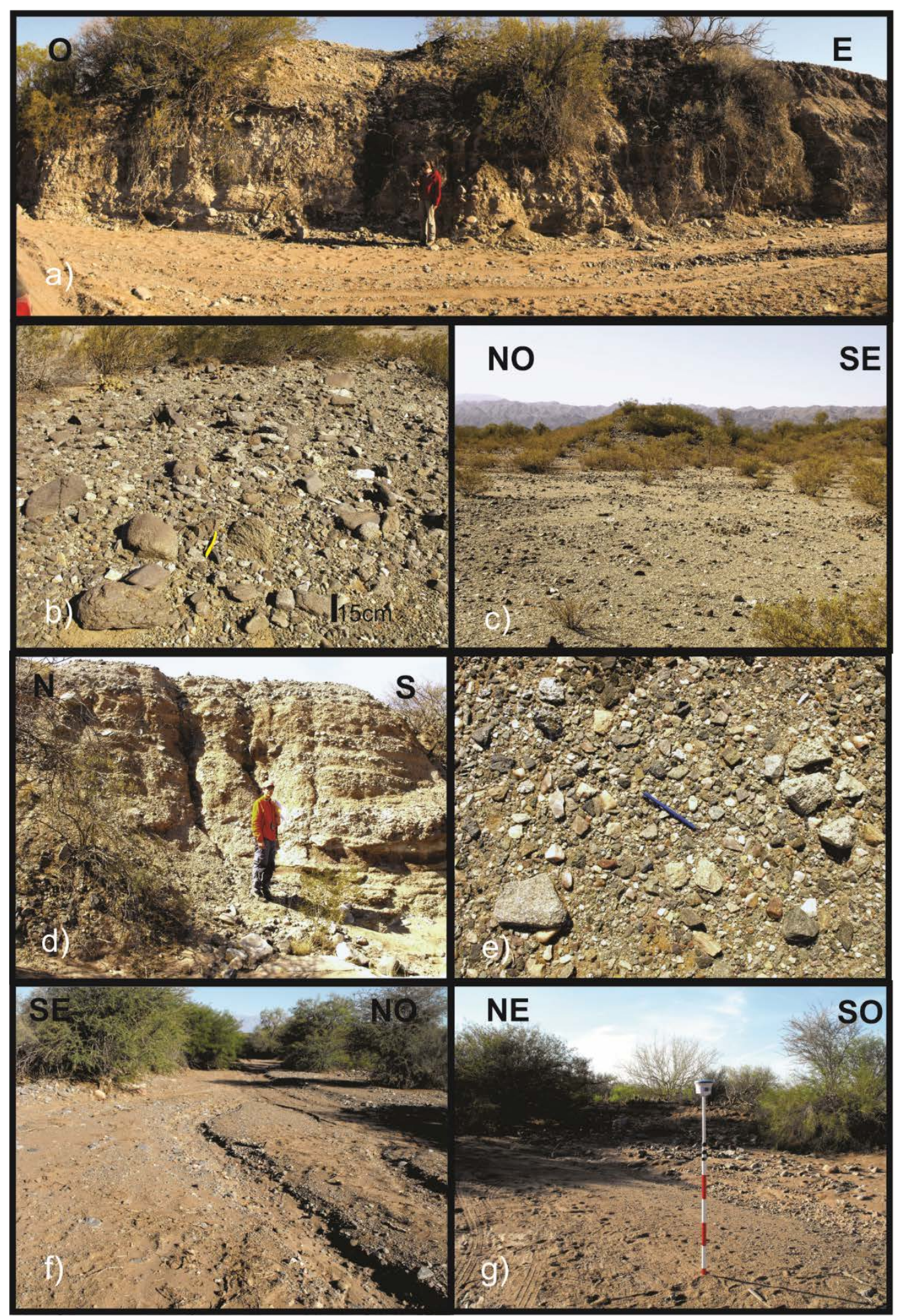

Figura 4 - En esta imagen se muestran los diferentes niveles aluviales Ql (a), Q2 (b y e), Q3 (d y e), y Q4 (f y g), analizados en el piedemonte occidental de la sierra de la Huerta.

\section{Unidad Deprimida}

En el área de estudio esta unidad corresponde a la depresión intermontana que constituye la llanura aluvial del río Bermejo, ubicada entre la sierra de Pie de Palo por el oeste y de La Huerta por el este, considerada como la subunidad llanura de inundación del río Bermejo (Figura 2a). 
Esta unidad se desarrolla sobre el sector SO de la zona de estudio (Figura 2a y b), la cual representa un pequeño sector de la extensa llanura de inundación del río Bermejo y correspondería al nivel de base de local.

La llanura de inundación está cubierta por depósitos de granulometrías que varían de arenas a arcillas (fluvio-eólicos) y depósitos salinos intercalados.

En esta unidad y sobre el borde occidental de la zona de estudio se ubica un campo de dunas, denominado Médanos Las Chacras. El campo de dunas de las Chacras tienen una forma elongada en sentido N-S, con una longitud de $18 \mathrm{~km}$ por $11 \mathrm{~km}$ de ancho; abarcando una superficie de $445 \mathrm{~km}^{2}$ (Figura 2a y b).

Las mayores elevaciones se encuentran en el sector NO con valores de $810 \mathrm{~m}$ snm, disminuyendo hacia el sector SE con alturas alrededor de $560 \mathrm{~m}$ snm.

Estos depósitos eólicos se interdigitan con los depósitos aluviales provenientes de la sierra de la Huerta, ubicada hacia el E. Se reconocieron en el área de estudio varios patrones de dunas (meso y megaformas eólicas), identificadas en función de la morfología, tamaño, orientación y dirección de migración. Se diferenciaron así 4 geoformas eólicas mayores (geoforma 1, 2, 3 y 4) y formas de erosión eólica asociadas a éstas, denominadas Geoforma 1 a 4 (Figura 2a)

Geoforma eólica 1: tiene el mayor desarrollo areal, ubicándose en la porción centro y norte del campo de dunas. Corresponde a grandes megaformas eólicas, transversales, con crestas sinuosas de rumbo $340^{\circ}$, con alturas que varían entre 30 y $50 \mathrm{~m}$, espaciadas entre $1500 \mathrm{~m}$ a 2000 $\mathrm{m}$. Un rasgo particular son las macro-formas transversales que se desarrollan por sobre estas megaformas. Estas macroformas eólicas tienen azimut $340^{\circ}$, en coincidencia con las direcciones medidas para las crestas de las megaformas.

Geoforma eólica 2: se ubica en el sector SSE del campo de dunas. Está conformada por megaformas eólicas transversales, con crestas rectilíneas y sinuosas de rumbo variable entre $\mathrm{N} 20^{\circ}$ y $25^{\circ}$. La distancia entre crestas sucesivas es de $1700 \mathrm{~m}$. Estas megaformas tienen las caras de sotavento hacia el NO. Al igual que en la unidad anterior se han observado encima de las megaformas, macroformas eólicas (dunas) transversales, pero en este caso con direcciones de $300^{\circ}$. Las caras de sotavento de las macroformas se encuentran mirando hacia el NE.

Geoforma eólica 3: se desarrolla sobre la porción occidental de los Médanos de la Chacras. Está conformada por macroformas transversales, con crestas rectilíneas con dirección $340^{\circ}$, y separación entre crestas de 500 a $700 \mathrm{~m}$.

Las caras de sotavento se ubican hacia el NE. Sobre ellas migran trenes de macroformas eólicas de menor porte de tipo transversal. Las macroformas eólicas menores se hallan mejor desarrolladas sobre la cara de barlovento de las megaformas eólicas y sus crestas coinciden en general con la alineación de las crestas de las formas mayores. Las caras de sotavento de las macroformas se ubican hacia el NE.

Geoforma eólica 4: corresponde a un extenso campo de dunas que cubre principalmente en forma discontinua el sector el sur y norte del campo de Médanos de las Chacras. A diferencia de las unidades geomórficas previamente descriptas no se observa aquí el desarrollo de megaformas sino sólo de macroformas eólicas, transversales, barjanes y longitudinales.

En el sector norte las macroformas tienen crestas sinuosas con azimut $70^{\circ}$, en tanto en el sector sur tienen crestas sinuosas pero con direcciones variables entre $114^{\circ}$ y $150^{\circ}$

Las formas de erosión reconocidas en la unidad de dunas están representadas por cuencas de deflación desarrolladas principalmente en la Geoforma 1, 2 y 3 (Figura 2a).

Las mismas tienen formas elongadas con longitudes que varían entre $260 \mathrm{~m}$ y $900 \mathrm{~m}$, para su eje mayor, y $150 \mathrm{~m}$ a $360 \mathrm{~m}$ para su eje menor. La base de las cuencas de deflación con respecto a las crestas de las macroformas eólicas que las circundan tiene desniveles menores a $50 \mathrm{~m}$.

En estos sectores más bajos se puede observar la presencia de pequeños cuerpos de agua temporaria o concentraciones salinas, rodeados por una mayor cantidad de vegetación en relación a la cubierta vegetal que presentan los médanos.

Este campo de dunas junto con los Médanos Grandes (sur de sierra de Pie de Palo) (Figura 1c) habría formado parte de un extenso sistema eólico (Tripaldi, 2002) que cubría gran parte del valle del río Bermejo. 


\section{Geomorfología tectónica}

En la zona de estudio se han reconocido evidencias de actividad tectónica cuaternaria a través de la evaluación de distintos marcadores morfotectónicos planares tales como dislocación de niveles aluviales y terrazas y lineares como anomalías en el drenaje, entre las que se puede mencionar: abras de viento, variaciones en el diseño de los ríos, ríos desviados, drenaje radial e inversión en el patrón de drenaje de los ríos.

\section{Marcadores planares}

Dislocación de niveles aluviales

Dentro de los niveles aluviales definidos en el piedemonte occidental de la sierra de La Huerta, tres de ellos (Q1, Q2 y Q3) están dislocados por fallas con rumbo NO y el labio hundido al oeste.

Como resultado, los niveles ubicados inmediatamente al E-NE de la falla Pan de Azúcar, se encuentran elevados con respecto a los niveles equivalentes que se ubican al O-SO de la traza de la falla (Figura 5 a, b, c y d).

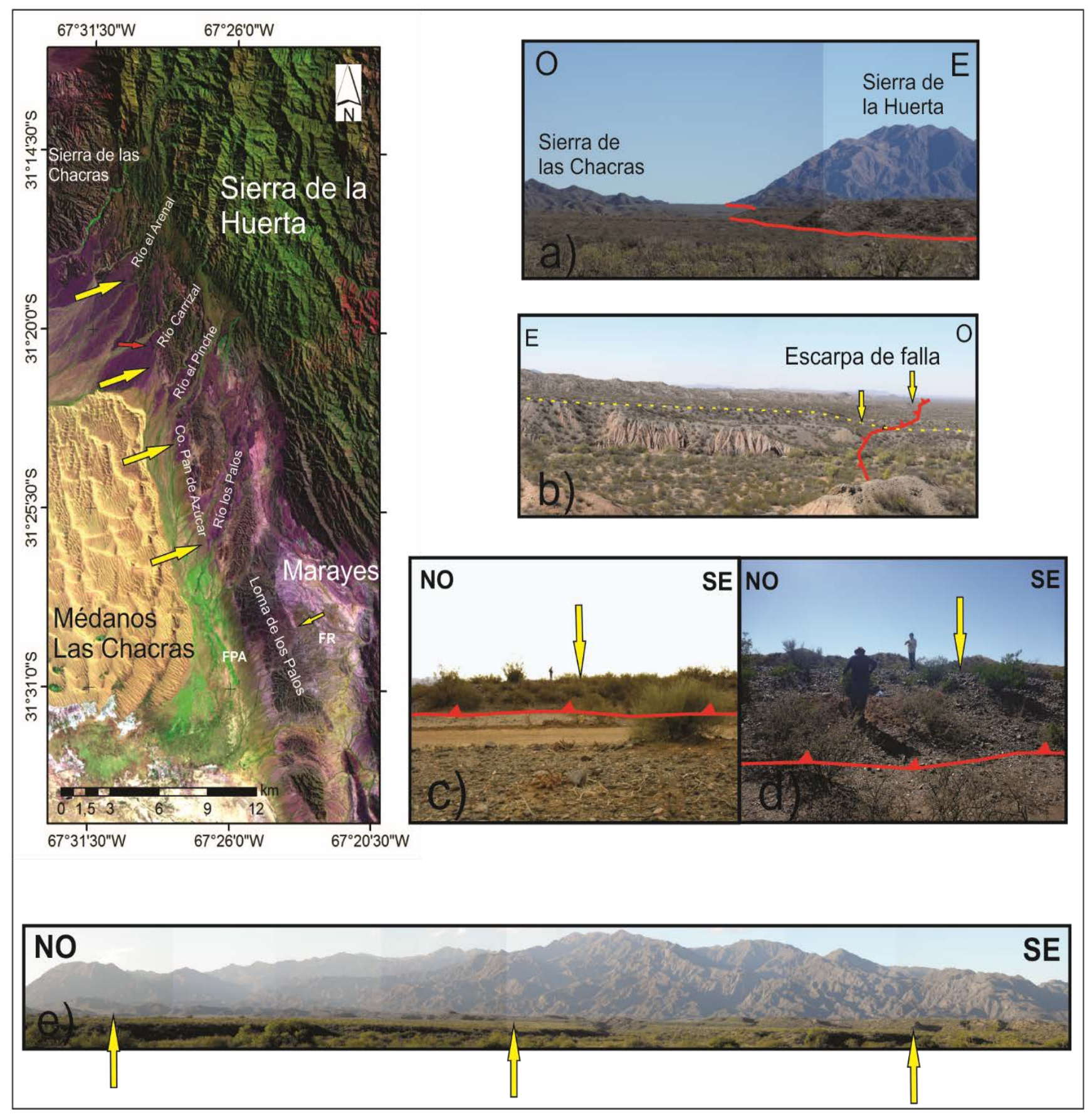

Figura 5 - Las flechas amarillas indican la traza de la falla Pan de Azúcar, em tanto la flecha roja indica donde se tomó una muestra para LOE. a) y b) corresponden a fotografias tomadas en el sector norte de la zona de estudio, em tanto que c) y d) hacia el sur. Se puede observar como la altura de la escarpa de falla disminuye hacia el sur. e) es una fotografia panorámica mostrando la escarpa de la falla Pan de Azúcar. 


\section{Terrazas}

Se han podido reconocer terrazas fluviales en aquellos sectores donde se produce al menos una pequeña elevación del terreno o bloque elevado de la falla, donde los ríos inciden más profundamente dejando sucesivas terrazas fluviales abandonadas.

A lo largo del río Quebrada del Barro se han podido reconocer cinco niveles de terrazas en el bloque elevado asociados a la falla Pan de Azúcar (Figura 6a).

Sobre el río Las Chacras, paralelo al río Quebrada del Barro, también se observaron cinco niveles de terrazas, en un sector ubicado al oeste de la traza de la falla Pan de Azúcar.

Estas terrazas estarían asociadas a una falla paralela a la falla principal, que no presenta ruptura superficial.

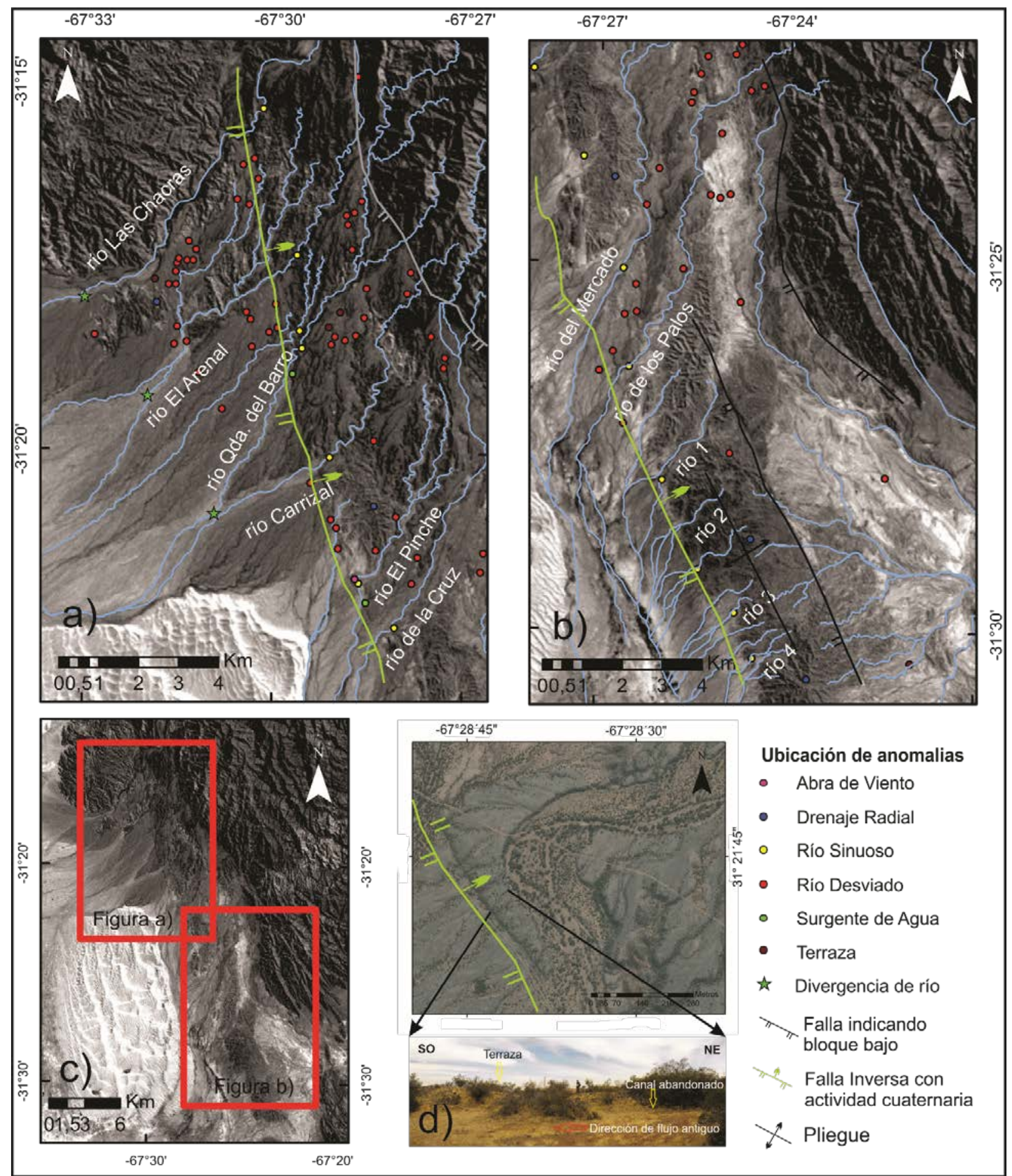

Figura 6 - Ubicación de los indicadores morfotectónicos en el sector norte a) y sur b) en la zona de estudio c). La figura d) muestra un abra de viento asociada a un río que ha sido desviado. 


\section{Marcadores lineales}

Variaciones en el diseño de los ríos

Una notable anomalía observada en el área de estudio es la modificación del diseño que presentan los cauces de los ríos aguas arriba y abajo de la traza de la falla Pan de Azúcar. Inmediatamente aguas arriba de la misma, los ríos tienen un trazado con alta sinuosidad en relación con el diseño aguas abajo, donde presentan baja sinuosidad (Tabla 2), como ejemplo se pueden citar los ríos Las Chacras, El Arenal, Quebrada del Barro, Carrizal, El Pinche, de la Cruz, del Mercado y de Los Palos (Figura 6 a y b). Por otro lado, el río Quebrada del Barro, el río de la Cruz y el río 1 y 3, muestran una disminución en la sinuosidad, en relación a los ríos que se encuentran ubicados más al sur y norte de los mismos.

Tabla 2 - Variación de la sinuosidad de ríos aguas arriba y abajo de la falla Pan de Azúcar. Se ha resaltado con gris los cambios notables en las diferencias de sinuosidad.

\begin{tabular}{c|c|c|c}
\hline Río & Sinuosidad tramo superior (Ss) & Sinuosidad tramo inferior (Si) & $\boldsymbol{\Delta S}=\mathbf{S s - S i}$ \\
\hline Las Chacras & 1,41 & 1,17 & 0,24 \\
\hline El Arenal & 1,38 & 1,18 & 0,20 \\
\hline Qda. del Barro & 1,21 & 1,10 & 0,12 \\
\hline Carrizal & 1,46 & 1,04 & 0,42 \\
\hline El Pinche & 1,35 & 1,10 & 0,25 \\
\hline de la Cruz & 1,12 & 1,11 & 0,01 \\
\hline del Mercado & 1,23 & 1,03 & 0,21 \\
\hline de los palos & 1,27 & 1,07 & 0,20 \\
\hline $\mathbf{1}$ & 1,06 & 1,04 & 0,02 \\
\hline $\mathbf{2}$ & 1,24 & 1,18 & 0,06 \\
\hline $\mathbf{3}$ & 1,20 & 1,07 & 0,13 \\
\hline $\mathbf{4}$ & 1,16 & 1,12 & 0,04 \\
\hline
\end{tabular}

Variación en la incisión de los ríos

Otro rasgo común en la zona de estudio es la diferencia en el grado de incisión de los ríos aguas arriba en relación con los ríos aguas abajo de la falla Pan de Azúcar. Inmediatamente aguas arriba de la traza de la falla los ríos tienen morfologías más sinuosas, son monocanalizados y están fuertemente incididos en rocas asignadas al grupo Marayes. Esto provoca valles de ríos más estrechos (entre 50 y $200 \mathrm{~m}$ ) y profundos (entre 25 y $5 \mathrm{~m}$ ) en el sector norte, disminuyendo hacia el sector central y sur de la zona de estudio. Aguas abajo de la falla, tienen sinuosidad moderada a rectilínea, son multicanalizados y presentan valles más anchos (entre 150 y $450 \mathrm{~m}$ ) y con menor incisión (entre 10 y $2 \mathrm{~m}$ ).

Variación en el rumbo de los ríos

En general los ríos ubicados en el piedemonte occidental de la sierra de la Huerta, tienen direcciones de drenaje preferenciales en sentido SO. Sin embargo, se han observado cauces que presentan direcciones de drenaje hacia el S y SE, considerándose anomalías en la red de drenaje, por estar fuertemente condicio- nados por las estructuras del área. Por ejemplo, el río Las Chacras, en las inmediaciones de la escarpa de falla Pan de Azúcar, se desvía circulando paralelo a ésta con una dirección S.

Otro ejemplo es el río el Pinche, el cual es desviado hacia el sur al acercarse a la escarpa de falla Pan de Azúcar. Al Oeste de la escarpa de la falla Pan de Azúcar, se han observado ríos que cambian de manera abrupta la dirección de drenaje de $\mathrm{SO}$ a $\mathrm{S}$ (paralelos al rumbo de esta falla) y luego drenan nuevamente en dirección hacia el SO (Figura 6 a y b). Por otro lado hacia el E de la escarpa de la falla Pan de Azúcar también se observan ríos con dirección de escurrimiento hacia el SO que son desviados, drenando en dirección $\mathrm{S}$.

Surgentes de agua

Otros indicadores geomorfológicos son las surgentes de agua, cuya disposición está relacionada con las estructuras de dirección NO, principalmente a lo largo de la traza de la falla Pan de Azúcar (Figura 6 a). En el río Quebrada del Barro, el aumento en la cantidad de humedad del terreno es aprovechado por la vegetación, la cual aumenta considerablemente. 
Este patrón de aumento en la concentración de la vegetación es observada a lo largo de la traza de la falla.

\section{Abras de viento (wind gaps)}

Las abras de viento corresponden a antiguos ríos que cruzaban la traza de la falla Pan de Azúcar, pero que han quedado como pequeños valles abandonados en el bloque elevado de la falla.

Un ejemplo notorio de abras de viento se observa en un tributario del río el Pinche, el cual al elevarse el bloque colgante de la falla generó la desviación del cauce del río y la desconexión con su antiguo cauce aguas abajo de la falla (Figura 6 a y d).

Inversión en el patrón de drenaje

La inversión del patrón de drenaje es otra anomalía que puede indicar el basculamiento de la superficie del terreno. Esto puede tener varios orígenes, como por ejemplo la formación de una cuenca flexural a los pies de bloque elevado o un cordón montañoso, la generación de pequeñas cuencas piggy-back o el incremento de la inclinación del limbo dorsal de un anticlinal o el limbo frontal de un sinclinal (Audemard, 1999). Esta anomalía de drenaje se reconoció en la unidad de lomadas, descriptas en el apartado de geomorfología.

En los flancos occidentales de estas lomadas los ríos drenan en la dirección de la pendiente regional, hacia el SO.

Por el contrario, los ríos ubicados en las laderas orientales drenan con dirección al E-SE para luego unirse con varios ríos de órdenes mayores y fluir en dirección hacia el S y SO. En el flanco occidental de la loma de los Palos los ríos drenan hacia el SO, en tanto que los ríos de su ladera oriental desaguan hacia el $\mathrm{E}$ (Figura 6 a y b).

Este es un claro ejemplo de inversión del patrón de drenaje, generado por la presencia de un anticlinal (Figura 6 b).

Análisis morfométrico y morfotectónico de las cuencas de drenaje del piedemonte occidental de la sierra de La Huerta

El análisis cuantitativo de las distintas cuencas de drenaje de una región, es importante ya que hay una estrecha relación entre la actividad tectónica y la geometría de las mismas (Bull, 2009). En el piedemonte occidental de la sierra de la Huerta se analizaron 12 cuencas, las cuales presentan formas elongadas en dirección NE (Figura 7).

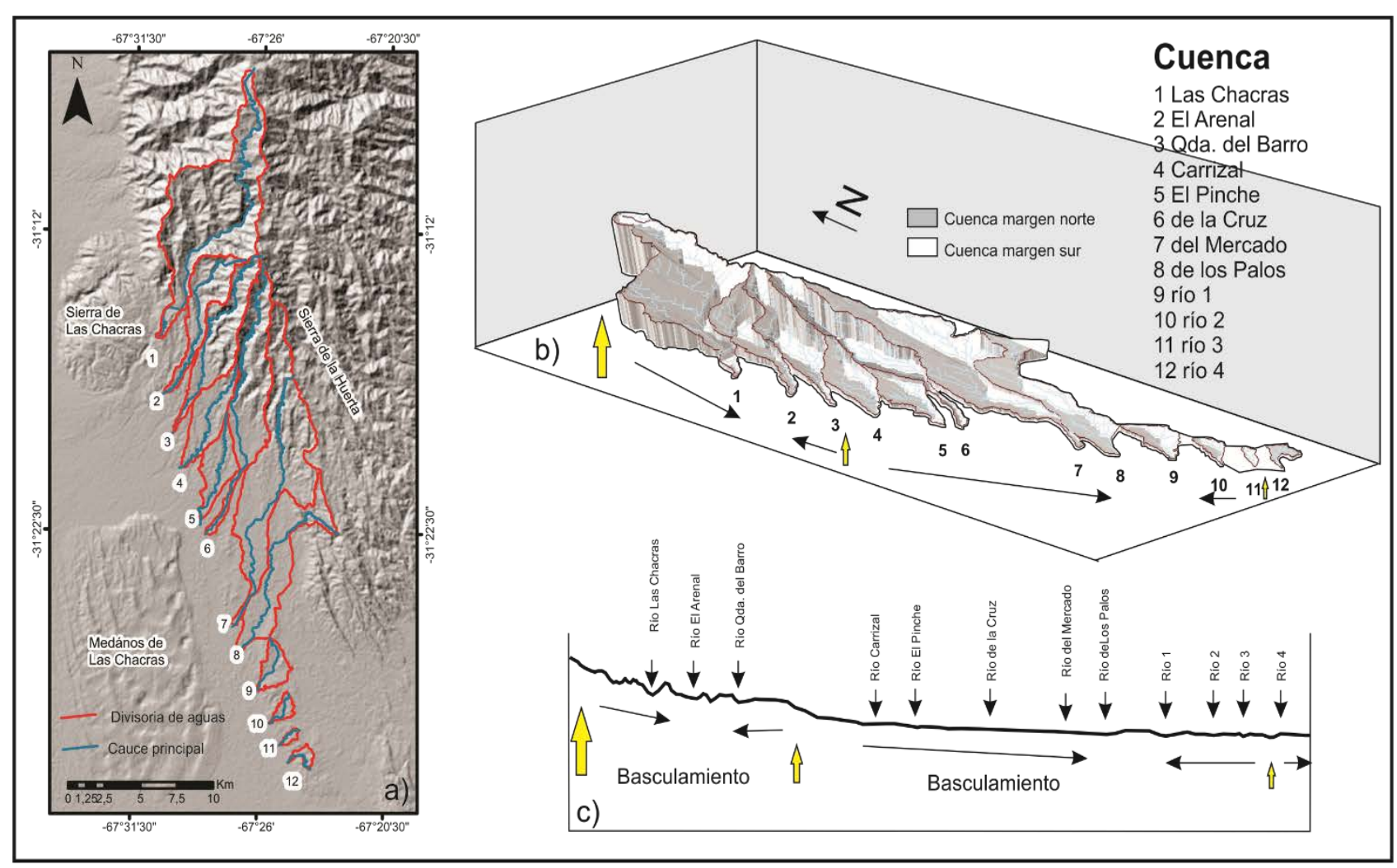

Figura 7 - a) Ubicación de cuencas de drenaje en el piedemonte occidental de la sierra de la Huerta. En la figura b) y c) las flechas amarillas indican zonas de levantamiento que provocarían la asimetría que presentan las diferentes cuencas. 
Las cuencas con geometrías elongadas (Bull, 2009), indican regiones influenciadas por la tectónica activa; donde el movimiento de una falla provoca la caída del nivel de base. Esto genera un aumento de la erosión de la red de drenaje, acelerando la degradación de las laderas de las cabeceras y divisorias de agua de las cuencas de drenaje (Bull, 2009). Diferentes índices morfométricos (Indice de compacidad Kc, Índice circularidad Rc, Radio de elongación Re y factor de forma Ff; Tabla 1), permitieron cuantificar la morfologías de las cuencas hídricas ubicadas en sector analizado. Como lo muestra la Tabla 3 todos los índices caracterizan las cuencas como formas elongadas a muy elongadas.

Otro rasgo particular que se observa en las diferentes cuencas hidrográficas ubicadas en la zona de estudio son sus morfologías asimétricas, donde una de las márgenes del río principal tiene mayor área que el lado opuesto. En la Tabla 4 se puede observar los valores de factor de asimetría (Hare y Gardner, 1985) calculados para las diferentes cuencas hidrográficas. Las redes de drenaje de los ríos Las Chacras, El Arenal, Carrizal, El Pinche, de la Cruz, Loma de los Palos y río 4, muestran factores de asimetrías mayores a 50. Esto indica una mayor área ubicada en la margen norte de cada uno de los colectores principales. De manera opuesta se puede observar que los valores de factor de asimetría obtenidos para las cuencas de los ríos Quebrada del Barro, del Mercado y los ríos 1, 2 y 3 muestran factores de asimetría menores a 50, indicando mayores áreas en la margen sur del colector principal.

Tabla 3 - Parámetros morfométricos de las diferentes cuencas analizadas.

\begin{tabular}{c|c|c|c|c|c}
\hline Cuenca & Nombre Cuenca & Kc & Rc & Re & Ff \\
\hline $\mathbf{1}$ & río Las Chacras & 1,96 & 0,26 & 0,45 & 0,16 \\
\hline $\mathbf{2}$ & río El Arenal & 2,01 & 0,24 & 0,41 & 0,13 \\
\hline $\mathbf{3}$ & río Quebrada del Barro & 1,95 & 0,26 & 0,39 & 0,12 \\
\hline $\mathbf{4}$ & río Carrizal & 1,46 & 0,46 & 0,51 & 0,20 \\
\hline $\mathbf{5}$ & río El Pinche & 1,64 & 0,37 & 0,47 & 0,17 \\
\hline $\mathbf{6}$ & río de la Cruz & 2,25 & 0,19 & 0,34 & 0,09 \\
\hline $\mathbf{7}$ & río del Mercado & 2,34 & 0,18 & 0,36 & 0,10 \\
\hline $\mathbf{8}$ & río de los Palos & 2,15 & 0,21 & 0,41 & 0,13 \\
\hline $\mathbf{9}$ & río 1 & 1,44 & 0,47 & 0,69 & 0,38 \\
\hline $\mathbf{1 0}$ & río 2 & 1,49 & 0,44 & 0,62 & 0,30 \\
\hline $\mathbf{1 1}$ & río 3 & 1,33 & 0,56 & 0,60 & 0,28 \\
\hline $\mathbf{1 2}$ & río 4 & 1,65 & 0,36 & 0,68 & 0,37 \\
\hline
\end{tabular}

Tabla 4 - Valores de factor de asimetría determinados para cada cuenca. Se resalta en gris aquellas cuencas que presentan basculamiento desde el sector norte.

\begin{tabular}{c|c|c|c}
\hline Cuenca & \multirow{2}{*}{ FA (factor de asimetría) } & \multicolumn{2}{|c}{ Levantamiento desde } \\
\hline río Las Chacras & 67,09 & Derecha & Norte \\
\hline río El Arenal & 50,86 & No inclinación & ---- \\
\hline río Qda. del Barro & 30,17 & Izquierda & Sur \\
\hline río Carrizal & 62,29 & Derecha & Norte \\
\hline río El Pinche & 54,61 & Sutil derecha & Norte \\
\hline río de la Cruz & 53,77 & Derecha & Norte \\
\hline río del Mercado & 28,97 & Izquierda & Sur \\
\hline río de los Palos & 60,46 & Derecha & Norte \\
\hline río 1 & 36,45 & Izquierda & Sur \\
\hline río 2 & 45,28 & Izquierda & Sur \\
\hline río 3 & 18,24 & Izquierda & Sur \\
\hline río 4 & 83,57 & Derecha & Norte \\
\hline
\end{tabular}




\section{Fallamiento Cuaternario}

Las evidencias de actividad tectónica durante el Cuaternario en el piedemonte occidental de la sierra de la Huerta son notorias. El sistema de fallamiento Las Chacras tiene como expresión geomorfológica más conspicua la falla Pan de Azúcar (Bossi, 1976; Bastías et al., 1990; Rothis, 2016); evidenciada por una escarpa de falla con cara libre al oeste, de rumbo NO (Figura 5 a, b, c y d). La traza de falla presenta una escarpa de morfología rectilínea con algunas inflexiones. Esta escarpa es suave y redondeada, de altura variable, desde 1,5 m en las cercanías al río El Pinche, hasta 27 $\mathrm{m}$ en la quebrada del Barro (Bastías et al., 1990; Rothis, 2016). Se destaca a lo largo de su traza una serie de lomadas limitadas en su flanco occidental por la falla Pan de Azúcar formadas por rocas triásicas, las cuales presentan morfologías elongadas con rumbo
NO. Además, la falla Pan de Azúcar afecta los depósitos cuaternarios, pudiéndose observar desplazados los niveles aluviales antiguos (Q1, Q2 y Q3, Figura 5) y no así el nivel aluvial actual.

La falla Pan de Azúcar es una falla inversa, cuyo azimut es $326^{\circ}$ y buza $25^{\circ} \mathrm{NE}$; presenta evidencias de ruptura superficial en tramos discontinuos a lo largo de aproximdamente 45 $\mathrm{km}$. En algunos sectores, como por ejemplo al norte del río el Carrizal, puede observarse el plano de falla que pone en contacto rocas triásicas de la cuenca de Marayes por encima de los niveles aluviales cuaternarios, asignados al Pleistoceno tardío (más de $47.830 \pm 8.340$ años). Además, se ha observado que las rocas triásicas que forman parte del bloque elevado tienen una intensa deformación frágil-dúctil, consideradas tectonitas por Bossi (1976) y Rothis (2016).

\section{DISCUSIÓN}

El área de estudio presenta tres grandes unidades morfoestructurales cuya génesis $\mathrm{y}$ evolución han estado íntimamente ligadas a la estructuración de la sierra de Valle Fértil-La Huerta, exceptuando los Médanos de las Chacras cuyo desarrollo ha estado influenciado principalmente por variaciones climáticas (Tripaldi, 2002).

La deformación tectónica cuaternaria presenta una distribución diferencial en el sentido Norte-Sur y Este-Oeste y se ubica principalmente en el piedemonte occidental de la sierra de La Huerta.

Hacia el sur de los $32^{\circ} \mathrm{S}$, la placa de Nazca aumenta el ángulo de subducción (Ramos et al., 2002), asociado a esto la deformación disminuye notablemente hacía el sur y el antepaís, de esta latitud (Ramos et al., 2002, Giambiagi \& Ramos., 2002). Esto ha quedado reflejado en la subunidad montañas altas, de lomadas y en la unidad de transición, ya que presentan mayores alturas en el sector norte disminuyendo hacia el sur.

Además, esto explicaría una mayor concentración de los niveles aluviales (Q1 y Q2) en el sector norte, y no así en el sector sur; y también el mayor número de evidencias de deformación cuaternaria en el sector norte del piedemonte occidental de la sierra de la Huerta.

El análisis de las cuencas hidrográficas presentes en el faldeo occidental de la sierra de la Huerta, ha permitido visualizar morfologías elongadas a muy elongadas para estas cuencas, las cuales según Bull (2009), son características de regiones con tectónica activa.

Además, el análisis de las cuencas muestra que ellas tienen un área mayor en el sector norte y centro y mucho menor en el sector sur. Otra característica observada es que cada cuenca presenta una distribución asimétrica del área a un lado y otro del margen del cauce principal.

En el sector norte y centro, las cuencas tienen una marcada asimetría, teniendo mayor superficie areal la margen norte de cada cauce principal. Por otro lado, las cuencas ubicadas hacia el sector sur, tienen mayor superficie areal en la margen sur de cada cauce principal.

Estas asimetrías serían generadas por levantamientos diferenciales en sentido N-S, tal como lo muestra la Figura 7, controlados principalmente por el levantamiento de la sierra de la Huerta, asociada a la Megafalla Valle Fértil y a la falla Pan de Azúcar y/o en menor medida a estructuras oblicuas a esta de orientación NE (Figura 1d).

También se observó una distribución de la deformación en sentido E-O, que está principalmente representada en el piedemonte occidental de la sierra de La Huerta, por la escarpa de la 
falla Pan de Azúcar.

Asociado a esta estructura se han reconocido numerosas evidencias de deformación cuaternaria, tales como la variación en el diseño de los ríos, diferencias en el grado de incisión y desviación de los ríos, desarrollo de abras de viento e inversión del drenaje (Figura 6 a, b y d).

En el sector norte del área de estudio, la falla Pan de Azúcar afecta los niveles aluviales más antiguos (Q4, Q3 y Q2). En el bloque elevado por la falla se ubicaron, cinco niveles de terrazas, como las ubicadas en el río Quebrada del Barro y además se apreció una mayor incisión de la red de drenaje, así como también una mayor sinuosidad en los cauces de los ríos principales en las cercanías de la escarpa de la falla Pan de Azúcar respecto del bloque hundido.

La fuerte incisión de los ríos inmediatamente aguas arriba de la traza de la Pan de Azúcar, se habría originado como respuesta al desplazamiento vertical de esta falla, lo que habría generado una variación local de la topografía de la zona de estudio con respecto al nivel de base local ubicado al oeste del área analizada (río Bermejo).

Por otro lado, el marcado incremento en la sinuosidad de los ríos al aproximarse a la falla Pan de Azúcar, se asociaría a una respuesta de los cauces fluviales para poder atravesar el abultamiento generado por el alzamiento vertical de dicha falla.

Esto generaría una disminución local de la pendiente, asociada a la elevación del bloque alto, y generaría el incremento en la sinuosidad.

Además, la desviación de los ríos podría estar asociada al crecimiento diacrónico y/o diferencial de pliegues y/o a que la tasa de levantamiento tectónico es más rápida que la tasa de erosión lineal (Audemard, 1999).

También se observaron anomalías al oeste de la escarpa de esta falla, pero de manera menos frecuente. A modo de ejemplo se pueden mencionar ríos desviados y desarrollo de terrazas.

Además, los cauces de los ríos principales, provenientes de la sierra de La Huerta, presentan una morfología particular en relación a los ríos aluviales típicos ya que no divergen a partir del ápice en el contacto entre piedemonte y el frente montañoso como se esperaría, sino en una posición más occidental (Figura 6 a y c), cercana al nivel de base local representado por la llanura aluvial del río Bermejo.

Esta distribución de las evidencias de deformación cuaternaria estaría indicando que la deformación migra hacia el oeste, donde las estructuras de fallamiento disminuyen su rechazo hacia la zona del valle del río Bermejo. En correspondencia con el análisis efectuado en este estudio, Snyder et al. (1990) mencionaron que hacia el oeste de la sierra de la Huerta se ubican dos fallas inversas buzantes al este; la ya mencionada falla Pan de Azúcar que presenta mayor deformación que otra falla ubicada más hacia el oeste, la cual no presenta evidencia de escarpas superficiales.

Por otro lado, Azeglio et al. (2010), observaron que al este de la sierra de la Huerta, fuera del área de estudio se desarrollan pliegues anticlinales asimétricos asociados a fallas inversas buzantes al este, con rechazos que disminuyen sensiblemente hacia el oeste. Este estilo de deformación es característico de Sierras Pampeanas donde las estructuras están representadas por fallas inversas con vergencia occidental (González Bonorino, 1950, Ramos et al., 2002, Siame et al., 2006).

\section{CONCLUSIONES}

La sierra de la Huerta se ubica en el extremo occidental de Sierras Pampeanas Occidentales, en la provincia de San Juan. En el faldeo occidental de esta sierra, las diferentes unidades de relieve reconocidas se habrían originado principalmente por efecto de la tectónica andina que actuó en el pasado y actúa a lo largo del borde occidental de Sudamérica.

Estas unidades de relieve han sido agrupadas en tres unidades morfoestructurales, unidad montañosa, unidad de transición y unidad deprimida. Esta división se basa principalmente en las diferencias en su expresión topográfica y composición litológica.

En la unidad montañosa y de transición se han diferenciado subunidades (montañas altas, cerrilladas y lomadas; y diferentes niveles aluviales, respectivamente).

Dentro de la unidad deprimida se ha reconocido la presencia de un campo de dunas (Médanos Las Chacras), el cual habría formado parte de un campo de dunas más extenso que cubría gran parte del valle del río Bermejo durante el Pleistoceno y Holoceno (Tripaldi, 2002; Tripaldi \& Forman, 2007).

Durante el Pleistoceno tardío y Holoceno, la 
tectónica andina continuó modificando el paisaje en esta región, evidenciado por diferentes marcadores morfotectónicos (planares y lineales); terrazas, dislocación de niveles aluviales, variaciones en el diseño de los ríos, incisión y desviación de ríos, surgentes de agua, abras de viento, inversión en el patrón de drenaje, anomalías en las cuencas de drenaje.

Los diferentes índices morfométricos aplicados en este trabajo indican que las cuencas de drenaje presentes en el sector occidental de la sierra de la Huerta presentan morfologías elongadas relacionadas posiblemente con la tectónica activa que afecta la región.
Además, se observó que estas cuencas de drenaje tienen morfologías asimétricas, con mayor desarrollo de la margen norte de cada cauce principal, indicando que existiría un basculamiento principalmente desde el sector norte.

La distribución espacial de las distintas unidades morfoestructurales reconocidas y el análisis de los indicadores morfotectónicos permiten determinar que la tasa de deformación disminuye de norte a sur y de este a oeste.

Esto estaría vinculado a la variación del ángulo de subducción de la placa de Nazca a la latitud del área de estudio y a la vergencia occidental de las estructuras en Sierras Pampeanas, respectivamente.

\section{AGRADECIMIENTOS}

Los Autores agradecen a CONICET y a SECITI-UNSJ Proyecto (797/14-CEFN) por el apoyo brindado para poder realizar los estudios presentados en este trabajo.

\section{REFERENCIAS}

ALVARADO, P. \& Beck, S. Source characterization of the San Juan (Argentina) crustal earthquakes of 15 January 1944 (Mw 7.0) and 11 June 1952 (Mw 6.8). Earth and Planetary Science Letters, v. 243, p. 615-631, 2006.

ANDERSON, M.; ALVARADO, P.; ZANDT, G.; BECK, S. L. Geometry and brittle deformation of the Subducting Nazca Plate, Central Chile and Argentina. Geophysical Journal International, v. 171, n 1, p. 419-434, 2007.

AUDEMARD, F. Morpho-Structural Expression of Active Thrust Fault Systems in the Humid Tropical Foothills of Colombia and Venezuela. Z. Geomorph. N. F., p. 227-224, 1999.

AZEGLIO, E. A.; GIMÉNEZ, M. E.; INTROCASO, A. Análisis estructural de la cuenca de las Salinas y su relación con la acumulación de sedimentos eólicos en el área Médanos Negros. Revista de la Asociación Geológica Argentina, v. 67, n. 2, p. 186-192, 2010.

BARANZANGI, M. \& ISACKS, B. Spatial distribution of earthquakes and subduction of the Nazca plate beneath South America. Geology, v.4, p. 686-692, 1976.

BASTÍAS, H.; ULIARTE, E.; PAREDES, J. D.; BASTÍAS, J. A.; PERUCCA, P. Neotectónica de la provincia de San Juan. In: CONGRESO GEOLÓGICO ARGENTINO, XI, 1990, San Juan. Actas... San Juan, p. 228-244.

BOSSI, G. Geología de la Cuenca de Marayes-El Carrizal, provincia de San Juan, Republica Argentina. In: CONGRESO GEOLÓGICO ARGENTINO, VI, 1976, Buenos Aires. Actas...Buenos Aires, p. 23-38.

BRUNIARD, E. D. La diagonal árida argentina: un límite climático real. Revista Geográfica, n. 95, p. 5-20, 1982.

BULL, W. B. Drainage basin. In Bull, W. B. Tectonically Active Landscapes. p. 28-57, 2009.

BURBANK, D. W. \& ANDERSON, R. S. Geomorphic Markers. In Burbank, D. W. \& Anderson, R. S., Tectonic Geomorpholgy. Malden: (ed.) Blackwell Publishing p. 1332, 2001.

COSTA, C. H.; AUDEMARD, M. F.; BECERRA, A.; LAVENU, M. N.; MACHETE, G. An overview of the main quatenary deformation of South America. Revista de la Asociación Geológica Argentina,v. 4, n. 61, p. 461-79,
2006.

COSTA, C. H.; MURILLO, M.; V.; SAGRIPANTI, G. L.; GARDINI, C. E. Quaternary intraplate deformation in the southeastern Sierras Pampeanas, Argentina. Journal of Seismology, n. 5, p. 399-409, 2001.

COSTA, C.; MACHETE, M.; DART, R.; BASTÍAS, H.; PERUCCA, L.; TELLO, G. H. Map and Database of Quaternary Faults and Folds in Argentina. U.S. Geological Survey Open-File Report 00-0108, 75 p., 2000.

COSTA, C. Rasgos estructurales del territoria argentino. Tectónica cuaternaria en las Sierras Pampeanas. In R. Caminos, Geología Argentina p. 779-784, 1999.

GIAMBIAGI, L. B. \& RAMOS, V. Structural evolution of the Andes in a transitional zone between flat and normal

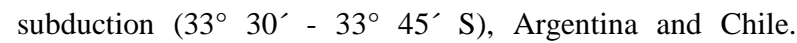
Journal of South American Earth Sciences, v. 15, n. 1, p. 101-116, 2002.

GONZÁLEZ BONORINO, F. Algunos problemas geológicos de las Sierras Pampeanas. Revista de la Asociación Geológica Argentina, v. 5, n. 3, p. 81-110, 1950.

GUTIÉRREZ ELORZA, M. Geomorfología Tectónica. In Gutiérrez Elorza, M. Geomorfología. Madrid: Pearson, p. 47-83, 2008.

HARE, P. W. \& GARDNER, T. W. Geomorphic indicators of vertical neotectonism along converging plate margins, Nicoya Peninsula, Costa Rica. Tectonic Geomorphology. PROCEEDINGS OF THE 15 GEOMORPHOLOGY SYMPOSIA SERIES. Annual Binghamton Geomorphology, p. 76-104, 1985.

ISACKS, B. L. Uplift of the Central Andean Plateau and bending of the Bolivian Orocline. Journal of Geophysical Research, n. 93, p. 3211-3231, 1988.

KELLER, E. A. \& PINTER, N. Active tectonics: Earthquakes Uplift and Landscape. New Jersey, 338p, 1996.

LANGER, C. J. \& BOLLINGER, G. A. Aftershocks of the western Argentina (Caucete) earthquake of 23 November 1977: some tectonic implications. Tectonophysics, v. 148, p. 131-146, 1988.

OUCHI, S. Response of alluvial rivers to slow active tectonic movement. Geological Society of America Bulletin, v. 96, 
p. 504-515, 1985.

PÉREZ, M.; ASTORGA, A.; MONLLOR, J.; ARAUJO, M. Relevamiento planialtimétrico-geológico de la fallas Las Chacras, en la quebrada del Barro. In: CONGRESO GEOLÓGICO CHILENO, XIII, 1997, Antofagasta. Actas...Antofagasta, n. 1, p. 210-214.

PERUCCA, L.; ROTHIS, M.; BEZERRA, F. H.; VARGAS, N.; LIMA, J. Late quaternary evolution of the La Cantera Fault System (Central Precordillera, Argentina): A morphotectonic and paleoseismic analysis. Tectonophysics, v. 661, p. 200-209, 2015.

PERUCCA, L. P.; ROTHIS, M.; VARGAS, H. N. Morphotectonic and neotectonic control on river pattern in the Sierra de la Cantera piedmont, Central Precordillera, province of San Juan, Argentina. Geomorphology, v. 204, p. 673-682, 2014.

PERUCCA, L. P. \& VARGAS, N. Neotectónica en la provincia de San Juan, centro-oeste de Argentina. Boletín de la Sociedad Geológica Mexicana, v. 66, n. 2, p.291-304, 2014.

RAMOS, V. Rasgos Estructurales del Territorio Argentino. In: Caminos, R. Geología Argentina. Buenos Aires, p. 715-784, 1999.

RAMOS, V. A.; CRISTALlinI, E. O.; PÉREZ, D. J. The Pampean flat-slab of the Central Andes. Journal of South American Earth Sciences, v. 15, n. 1, p. 159-78, 2002.

REGNIER, M.; CHATELAIN, J. L.; SMALLEY, R.; CHIU, J. M.; ISACKS, B. L.; ARAUJO, M. Seismotectonics of Sierra de Pie de Palo a basement block uplift in the Andean foreland of Argentina. Bulletin of the Seismological Society of America, v. 82, n. 6, p. 2547-2571, 1992.

ROTHIS, L. M. Análisis de la actividad tectónica cuaternaria en el sector sur de la falla Las Chacras y evaluación de la peligrosidad sísmica. Sierras Pampeanas Occidentales. Provincia de San Juan. San Juan, 2016. 185 p. Tesis (Doctoral). Facultad de Ciencias Físicas y Naturales, U.N.S.J

ROTHIS, L. M.; SANTI MALNIS, P.; PANTANO ZUÑIGA, A.; PERUCCA, L. P. (2012). Evidencias de reactivación de la falla maestra de la cuenca triásica de Marayes, al norte del Cerro Pan de Aucar, Sierras Pampeanas Occidentales, San Juan, Argentina. In: REUNIÓN DE TECTÓNICA, XV 2012, San Juan. Actas... San Juan, p. 131.

SIAME, L. L.; SÉBREIER, M.; BELLIER, O.; BOURLÈS, D.; COSTA, C.; AHUMADA, E. A.; GARDINI, C. E.; CISNEROS, H. Active basement uplift of Sierra Pie de Palo (Northwestern Argentina): Rates and inception from 10Be cosmogenic nuclide concentrations. Tectonics, v. 34, n. 6, p. 1129-1153, 2015

SIAME, L.; BELLIER, O.; SEBRIER, M. Active tectonics in the argentine precordillera and western sierras pampeanas. Revista de la Asociación Geológica Argentina, v. 61, n. 4, p. 604-619, 2006.

SIAME, L. L.; BELLIER, O.; SÉBRIER, M.; ARAUJO, M. Deformation partitioning in flat subduction setting: Case of the Andean foreland of western Argentina $\left(28^{\circ} \mathrm{S}-33^{\circ} \mathrm{S}\right)$. Tectonics, v. 24, p. 1-24, 2005.

SMALLEY JR., R.; PUJOL, J.; REGNIER, M.; CHIU, J. M.; CHATELAIN, J. L.; ISACKS, B. L.; ARAUJO, M.; PUEBLA, N. Basement seismicity beneath the Andean Precordillera thin-skinned thrust belt and implications for crustal and lithospheric behavior. Tectonics, v. 12, p. 63-76, 1993.

SNYDER, D. B. Thick-skinned deformation observed on deep seismic reflection profiles in Western Argentina. Tectonics, v. 9, n. 4, p. 773-788, 1990.

TREO, C. H.; WEIDMAN, N.; PEREZ, M. A.; MARTOS, L.; GALLARDO, C.; AGÜERO, R. Análisis morfoestructural del sistema de fallamiento Las Chacras como fuente sísmica potencial. San Juan: Facultad de Ciencias Exactas, Físicas y Naturales, U.N.S.J., 1997.

TRIPALDI, A. Sedimentología y evolución del campo de dunas de Médanos Grandes (provincia de San Juan, Argentina). Revista Asociación Argentina de Sedimentología, v. 9, n. 1, p. 65-82, 2002.

TRIPALDI, A. \& FORMAN, S. L. Geomorphology and chronology of Late Quaternary dune fields of western Argentina. Palaeogoegraphy, Palaeoclimatology, Palaeocology, v. 251, n. 2, p. 300-320, 2007.

VERGÉS, J.; RAMOS, V. A.; MEIGS, A.; CRISTALLINI, E.; BETTINI, F. H.; CORTÉS, J. M. Crustal wedging triggering recent deformation in the Andean thrust front between $31^{\circ} \mathrm{S}$ and $33^{\circ} \mathrm{S}$ : Sierras Pampeanas-Precordillera interaction. Journal of Geophysical Research, v. 112, p. 1-22, 2007.

VILLALBA, D. \& SAGRIPANTI, G. L. Análisis morfológico de escarpas asociadas a una falla de intraplaca con actividad cuaternaria: falla Las lagunas, Córdoba. Revista de la Asociación Geológica de la Argentina, v. 71, n. 1, p. 82-91, 2014.

VUJOVICH, G.; CHERNICOFF, C.; TCHILINGUIRIAN, P.; GODEAS, M.; MARÍN, G.; PEZZUTTI, N.; SEPÚLVEDA, E.; LÓPEZ, H; CARDÓ, R.; DIAZ, I. Hoja Geológica 3166III. Chepes, provincias de La Rioja, San Juan y San Luis. Buenos Aires: SEGEMAR, 65 p., 2007.

Submetido em 21 de fevereiro de 2017 Aceito em 18 de outubro de 2017 